\title{
Romanización augustea y onomástica personal en la Meseta norte. El nomen Iulius
}

\author{
Henar Gallego Franco \\ Universidad de Valladolid \\ henarg@fyl.uva.es
}

\section{RESUMEN}

Se evalúa la presencia del nomen Iulius en la onomástica personal recogida en las fuentes epigráficas romanas de la Meseta norte, tanto desde el punto de vista cuantitativo como cualitativo, y se explora su posible relación con la influencia romanizadora en la zona del emperador Augusto y de la gens Iulia imperial.

Palabras clave: Onomástica. Romanización. Augusto. Meseta norte.

\section{Augustean Romanization and Personal Names in the Northern Meseta. The Nomen Iulius}

\begin{abstract}
This work evaluates the presence of the nomen Iulius in the personal names contained in the epigraphical sources of the northern Meseta, in Roman Spain, from a quantitative and a qualitative point of view, and explores its posible relationship with the romanizing influence of the emperor Augustus and the imperial gens Iulia in this area.
\end{abstract}

Key Words: Personal names. Romanization. Augustus. Northern Meseta. Roman Spain. 
Es de conocimiento general que la decisiva reorganización administrativa de Hispania desarrollada por Augusto, que pervivió en sus líneas esenciales hasta finales del s. III d.C., fue especialmente intensa en los territorios de reciente anexión, los del tercio norte peninsular, incorporados tras el cierre exitoso por parte del emperador de las guerras contra cántabros y astures, y entre los cuales se hallaban varias zonas de la Meseta norte. La reestructuración administrativa augustea de esta área se cimentó en una implementación del proceso de urbanización, que se tradujo en la configuración de una sólida red de ciudades o civitates como pilares del sistema de organización y administración del territorio a nivel local. A pesar de ello, la Meseta norte no fue incluida entre los territorios receptores de la política de fundaciones coloniales y de municipalización de derecho romano de César y de Augusto en Hispania. ${ }^{1}$ En este sentido, las únicas promociones jurídicas preflavias conocidas hasta el momento en este territorio son las de tres ciudades arévacas, Clunia (Peñalba de Castro, Burgos), Uxama Argaela (El Burgo de Osma, Soria) y Termes (Montejo de Tiermes, Soria). Éstas alcanzarían la categoría de municipios latinos a comienzos de la época altoimperial, en un momento en que la documentación y el consenso de la investigación lleva a la época de Tiberio, pero que se ha sugerido pudiera adelantarse a finales del gobierno de Augusto. Luego Clunia accedería al estatus de colonia romana, seguramente bajo el emperador Galba. ${ }^{2}$ También debemos señalar que varias civitates de la Meseta norte portan epítetos que aluden a la figura de Augusto, en especial el término Augustus/a, pero es obvio que en nuestro territorio éstos no necesariamente hacen referencia a que se trate de núcleos promocionados jurídicamente por Augusto, sino más bien conmemoran una fundación o reorganización interna de la ciudad debida a este emperador, caso manifiesto de Asturica Augusta (Astorga, León) y Iuliobriga (Retortillo, Santander), ${ }^{3}$ y más difícil de probar en los de Augustobriga (Muro de Ágreda, Soria), Porta Augusta, Nova Augusta (Lara de los Infantes, Burgos) y Segisama Iulia (Castrojeriz, Burgos), aunque en el caso de éstas dos últimas ciudades su existencia se constate en las fuentes antiguas ya en los inicios del Imperio. ${ }^{4}$ También

1 Martino 2004, 27, 33, 87, 111; el mismo autor en pp. 41-42 proporciona un listado de las civitates de la Meseta norte de comienzos del Imperio, atestiguadas bien a través de las fuentes literarias o de la epigrafía.

2 De las tres sólo Clunia sería una fundación ex novo, mientras que Termes y Uxama Argaela eran ya potentes poblaciones en el Hierro II. Vid. MarTino 2004, 115, 253, 350, 364, en especial 411, donde se propone que Augusto resulta estar más vinculado a las promociones municipales latinas en Hispania que su sucesor Tiberio, de manera que sus promociones podrían ser una iniciativa de fin de reinado de Augusto, que se desarrolla ya bajo Tiberio, como ocurre en algunos casos del vecino convento caesaraugustano (GARCíA FERNÁNDEZ 2001, 85 ss). En consecuencia se insiste en que la tribus de origen de las tres ciudades es la Galeria, propia de las promociones augusteas, y preflavias en general (MARTINO 2004, 107-108).

3 Sobre las causas de la presencia de epítetos imperiales en nombres de las ciudades de la Meseta norte Martino 2004, 102. Tanto Asturica Augusta como Iuliobriga son fundaciones ex novo de época de Augusto y estrechamente vinculadas al ejército (MARTINo 2004, 218-220, 286; GonZÁLEZ FernándeZ 2012, 257-265; CEPEDA ET ALII 2009, 97-99).

4 Augustobriga y Porta Augusta son conocidas a partir de los datos de Ptolomeo (s. II d.C.) y el conocimiento arqueológico sobre la primera es escaso, vid. MARTINO, 2004, 222-223; NÚÑEZ - CURCHIN 2007, 451-455, especialmente p. 452 donde se recoge la posibilidad de que fuera un antigo nucleo pelendón que recibiera un nuevo nombre en época de Augusto, o que se tratara de una fundación ex novo de época augustea, vinculada quizá al desarrollo de la red viaria; en todo caso, falta la confirmación de la arqueología. La segunda, Porta Augusta, supuestamente perteneciente a los vacceos, está sin localizar, aunque su nombre 
es posible que el epíteto pueda tener en algunos casos un carácter simplemente honorífico.

Por otro lado resulta probado a través de las fuentes epigráficas que en Hispania los nuevos ciudadanos romanos provinciales no eran tan proclives a adoptar como nomen que expresara su superior situación jurídica el del emperador romano de turno, al que debían la promoción o gobernaba en ese momento, como en otras provincias del Imperio de romanización más tardía, caso de las del limes del Rhin o del Danubio. ${ }^{5}$ A pesar de ello es un dato contrastado que Iulius es el más frecuente de los nomina gentilicios recogidos en las fuentes epigráficas hispanorromanas. Sin embargo, la adopción por parte de un nuevo ciudadano provincial hispano del nomen Iulius no necesariamente implica una promoción del mismo asociada a la figura de Augusto. Éste era igualmente el nomen del propio César, cuya política provincial también tuvo aplicación en Hispania, y de otros emperadores de inicios del Principado, como Tiberio. Probablemente ni siquiera tiene que señalar una promoción jurídica relacionada de forma directa con un miembro de la gens Iulia imperial, puesto que, popularmente asociado a ésta, en sí mismo Iulius debía de ser un gentilicio romano apreciado por los provinciales como signo de romanidad prestigiosa, y susceptible de ser adoptado por algunos de ellos al alcanzar la ciudadanía romana, aunque ésta no tuviera una relación directa con la dinastía Julia. Pero además, detrás del dato de que Iulius es el nomen repetido con mayor frecuencia en la onomástica personal de la epigrafía hispanorromana, subyacen en realidad una gran variedad de situaciones diferentes según las distintas áreas peninsulares. ${ }^{6}$ Así se refleja precisamente en la onomástica personal contenida en las fuentes epigráficas de la Meseta norte.

En la mitad occidental de la misma la presencia epigráfica de Iulius únicamente resulta sobresaliente en dos civitates, Salmantica y Asturica Augusta. Iulius es el nomen romano más repetido en los documentos epigráficos de la provincia de Salamanca, concentrándose los testimonios especialmente en Salmantica, civitas conocida ya

se ha puesto en relación también con el comienzo de alguna vía de comunicación (MARTINo 2004, 321). Por el contrario, la existencia de Nova Augusta y de Segisama Iulia se constata ya en los inicios del Imperio (Martino 2004, 41-42). Para Nova Augusta, de los arévacos, se apunta a una fundación ex novo, fruto del traslado de la población desde el cercano castro del Cerro de la Muela (Edad del Hierro) durante la época altoimperial (NÚÑEZ - CURCHIN 2007, 498-499). En cuanto a Segisama Iulia, en principio vaccea (MARTINO $2004,335)$, se ha vinculado su origen al ejército y al fin de las operaciones militares de las guerras cántabras, en época augustea (NÚÑEZ - CURCHIN 2007, 564-565). En todo caso, tanto la reorganizazión del territorio tras las guerras cántabras y en relación con las unidades militares implicadas en la contienda y sus campamentos, como el desplazamiento de poblaciones desde los castros elevados a los valles próximos, y el establecimiento de los fundamentos de la red viaria de la zona son políticas augusteas bien conocidas en la Meseta norte. La medida de desplazamiento forzado del poblamiento de castros a la llanura fue aplicada en diversas ocasiones a lo largo de la conquista romana de Hispania, y ya utilizada por César en nuestro territorio (por ejemplo para los castros vetones del entorno de Ávila, Hernando Sobrino 2005, 17; Gómez Pantoja 2007, 342-343). Descartamos en este grupo de epítetos relacionados con Augusto a Flaviaugusta (Poza de la Sal, Burgos), de los autrigones, cuyo nombre hace referencia a su promoción a municipio latino bajo otros "Augustos", los emperadores Flavios (MARTINO 2004, 272-274).

5 ABASCAL 1994, 28-30: Iulius es el único nomen de tipo imperial que se encuentra entre los diez gentilicios más numerosos en Hispania; AlföLdy 1966, 46-47; GaLLEGo FranCO 2001; García MarTínez 2000.

6 Abascal 1994, 29. 
en los inicios del Imperio y probablemente municipio flavio. ${ }^{7}$ Allí los Iulii debían de constituir una de las familias de notables de la misma, habida cuenta de la singular calidad de algunos de los soportes epigráficos relacionados con sus miembros y su carácter de patronos de libertos. ${ }^{8}$ En la provincia de Léon, Iulius resulta ser igualmente el nomen romano más repetido en las fuentes epigráficas, concentrándose el mayor número de testimonios en Asturica Augusta, ciudad de origen campamental y fundación augustea, que alcanzó la situación de municipio flavio. ${ }^{9}$ En Asturica, como en Salmantica, algunos Iulii pertenecían a las élites socioeconómicas y administrativas oriundas de la civitas y ejercían el patronazgo de libertos. ${ }^{10}$ Como rasgo particular hay que mencionar la notable presencia de foráneos entre los Iulii localizados en Asturica, lo que no es de extrañar, dada la importancia de la ciudad como centro administrativo del Noroeste. ${ }^{11}$ Esta notoriedad cuantitativa del nomen Iulius en las

7 Martino 2004, 238-330.

8 Palao 2007, 249, 254-255: caso de los monumentos de L(ucius) Iulius Capito salmantic(ensis), dedicado por su hermana Iul(ia) Rusticilla (IRPSa 238, Salamanca, mediados s. II - comienzos s. II d.C.), y de Iulia Bassina a su marido (IRPSa 220, mediados s. II - comienzos s. III d.C.). Los cognomina griegos de C(aius) Iulius Narcissus, su mujer Iulia Thetis, y su hijo homónimo C(aius) Iulius Narcissus (IRPSa 214, 237, Salamanca, mediados del s. II - comienzos s. III d.C.), y de Iul(ius) Achilles Iul(ii) Eutychi [f.] (Aldeagallega, Ss. II-III) apuntan a que se trate de individuos de origen servil, libertos o descendientes de libertos de los Iulii salmanticenses, Solin 1982, 1100, 1365, 464, 547, 801 y 1362; PAlao 2007, 258. Aparte de en Salmantica, el gentilicio se constata también, aunque puntualmente, en la zona nororiental de la provincia, en los enclaves indígenas romanizados de Hinojosa (IRPSa 102, Iulii [f.], s. II) y Saldeana (IRPSa [I]ulia ...dia [F]usci [f.?], finales s. II - comienzos s. III d.C.), así como en dos aras votivas consagradas a Iuppiter Optimus Maximus en Boadilla (ERPSa 2, C(aius) Iu[lius...], mediados s. II d.C.) y Cepeda (HEp 13, 541, Iulius Vegetus, ss. II-III), que constituyen dos de los documentos más romanizados dentro de la religiosidad de la provincia de Salamanca constatada a través de la epigrafía, PALAO 2007, 259-260.

9 ERPLe pp. 547-553. Sobre el status de Asturica vid. Martino 2004, 216-218.

10 La élite de los Iulii asturicenses aparece representada por un ciudadano romano de promoción flavia que fue propuesto para el flaminado provincial. ERPLe 183, s. II d.C.: [C(aius) I] ulius C(aii) f(ilius) [Qu]ir(ina tribus) Fidus ast(uricensis), [s]acerdos Rom[ae] et Aug(usti), flamen des(ignatus) prov(inciae) H(ispaniae) C(iterioris), quien es dedicado por sus hijas, las Iuliae [maior et minor]. Precisamente un Iulius N[e]pos, a finales del s. I o inicios del s. II d.C. (ERPLe 29, La Milla del Río) figura como curante en una votiva al Deus Vagodonnaego puesta por la res publica Asturicae Augustae a través de dos magistrati de la misma. Destaca también Tib(erius) Iulius Vegetus, patrono del liberto Sabinus (ERPLe 184, s. II d.C.). Los restantes Iulii, presumiblemente de origen asturicense, parecen de condición más modesta: ERPLe 177, Iul(ia) Amma, s. II d.C., una indígena romanizada (nótese su cognomen de origen prerromano, AlBerTos 1964, 219) cuyo hijo, Min(ucius) [Do]ciri fil(ius) no tiene los derechos de ciudadanía romana, a juzgar por su esquema onomástico de idiónimo + patronímico; ERPLe 185, Iulius Oculatius, s. II d.C., cuyo cognomen puede tener carácter de decknamen (Solin - SAlomies 1988: 130 y PÉrez Rojas 1993, 237 nota 180); ERPLe 229, Sestia Iulia, s. II d.C. avanzado, probablemente una liberta, por su coincidencia de nomen con su marido, que porta un cognomen griego, Ses(tius) Chrestus (Solin 1982, 929, 1351 y 1370); ERPLe 299, Iul(ius) Si(lo?), Iul(ius) Flo(rus?), un fragmento de inscripción monumental datado en el s. I d.C. avanzado, ¿dos libertos que honran a un patrono? Podemos añadir al niño de corta edad Dativus Iu [l]lianae filius (ERPLe 149, s. II), probablemente un hijo de esclava o un hijo natural, habida cuenta de su filiación materna y al hecho de que su madre sea la única dedicante del monumento.

11 ERPLe 40, 60, 61, Iulius Silvanus Melanio, proc(urator) Augg(ustorum) provinc(iae) Hisp(aniae) Citer(ioris), finales del s. II - comienzos del s. III d.C.; ERPLe 171, Iul(ius) Martial(is), centurio exs cohorte Thracum, s. I d.C. avanzado; podría ser foránea la procedencia de Iulia Protis (ERPLe 179, s. II d.C.), mujer del liberto imperial P(ublius) Ael(ius) Eustomus; ERPLe 180, C(aius) Iulius C(aii) l(ibertus) Battalus domo Roma, y sus dedicantes, probablemente colibertos, C(aius) Iulius Solinus y L(ucius) Iulius Atticus, seguramente también de origen foráneo, datada en el s. I d.C. Al margen de en Asturica Augusta, y atendiendo 
provincias de León y Salamanca contrasta, sin embargo, con su poco significativa presencia en el otro conjunto epigráfico provincial de la Meseta occidental, el de Zamora. ${ }^{12}$

Dirigimos a continuación nuestra atención a la franja central de la Meseta, integrada por los territorios abulense, segoviano, vallisoletano y palentino. Aquí el conjunto provincial de Ávila, vecino del de Salamanca, registra también una muy pobre presencia del nomen Iulius. ${ }^{13}$ Por el contrario en los conjuntos provinciales de Segovia y Palencia Iulius se encuentra entre el grupo de nomina más repetidos, aunque sin protagonizar éste. Pero hay que tener en cuenta que, siendo la tónica en la epigrafía de ambas provincias la gran variedad de los nomina constatados, la presencia de Iulii queda reducida a unos pocos casos. Éstos se centran en las civitates de Segovia y Palantia,${ }^{14}$ ambas notables núcleos indígenas prerromanos que alcanzaron el estatu-

al territorio leonés que se integra en la Meseta norte, el gentilicio Iulius se constata también en algunos lugares puntuales. Así en el área del municipio flavio de Bergidum Flavium: ERPLe 14, M(arcus) Iuliu[s] [---]ter[n] us, finales del s. II - comienzos s. III d.C., un indígena romanizado, portador de un cognomen de parentesco (ABASCAL 1984), que consagra a la divinidad indígena Cossue; sobre el estatus de Bergidum, MarTino 2004, 234. En la villa de Cimanes de la Vega, ERPLe 201, Iulia Mariana, s. III d.C. En Crémenes, ERPLe 377, $\mathrm{M}$ (arcus) Iulius Cr(escens), vet(eranus) leg(ionis) XX, s. I d.C., quizá un vadiniense que buscó pasar su años de retiro en su lugar de origen, aunque para Martino 2012, 311 nota 35 es un militar de origen foráneo. Podemos añadir a Iulian[us], en una villa en Villaquejida, s. III d.C. (ERPLe 239). También son portadores del nomen Iulius distintos militares de epígrafes, sobre todo honoríficos, procedentes de Luyego de Somoza y Villalís de la Valduerna (Villamontán de la Valduerna), en la órbita de Asturica y ligados a las explotaciones mineras, pero no podemos saber si estos individuos eran oriundos del territorio leonés o de otras áreas de la Meseta norte, podrían ser incluso de procedencia foránea: ERPLe 63, Iul(ius) Marcus, centurio legionis VII G(eminae) F(elicis), Luyego, 138-161 d.C.; ERPL 181, Iul(ius) Capito, mil(es) coh(ortis) I C[eltiberorum?], Luyego, s. I d.C. avanzado; ERPLe 64 y 66, [I]uli(us) Iulianus, sign(ifer) leg(ionis) VII G(eminae) F(elicis), Villalís, 163/165 d.C.; ERPLe 67, Iuli(us) Sedulus, tesserari(us) c(ohortis) I C(eltiberorum), Villalís, 167 d.C.

12 IRPZa 88, Iulia Fextil[a], en Moral de Sayago, núcleo indígena romanizado del que no conocemos promoción jurídica, ss. II-III d.C.; IRPZa 143, T(itus) Iulius Iustus, en Rosinos de Vidriales, la antigua Petavonium, ss. I-II. Petavonium fue lugar de acantonamiento de distintas unidades militares desde el final de las guerras cántabras, pero no tenemos datos sobre el estatus jurídico del núcleo de población, MarTino 2004, 313.

13 En dos aras de Narros del Puerto, ERAv 131, Iulius, consagrada al Deus Iuppiter, mediados s. II-III d.C. y ERAv 132, Iul(ius) Gaianus, dedicada a los Lares Viales, s. III d.C. Se da la circunstancia de que en el santuario de Narros del Puerto se constata también el culto a la divinidad vetona Ilurbeda, vinculada precisamente al territorio salmantino, en el que ya hemos visto el impacto importante del nomen Iulius, vid. HeRnANDo SOBRino 2005, 162.

14 En la provincia de Segovia: ERSg 7, [I]ulius [---] en Cauca (Coca), s. II d.C., municipio, quizá de promoción flavia (MARTINo 2004, 250); ERSg 54, C(aius) Iuli [us ---] y C(aius) Iulius, en una doble dedicación a Hércules procedente de Montejo de la Vega de la Serrezuela, enclave rural al noreste de la provincia, con antecedentes de poblamiento prerromano y estratégica disposición respecto a la red viaria romana, en concreto la vía que unía Clunia y Segovia (López Ambite 2002, 77-104, en especial p. 82), finales s. I - inicio s. II d.C.; y ya en Segovia ERSg 84, [I]ul(ius) Flavus, dueño del esclavo Victor, s. II d.C.; ERSg 179, Iul(ia) Helpis y su hijo C(ornelius?) Iulianus, s. II d.C., y por el cognomen griego podría ser que Helpis (Solin 1982, 1205 ) fuera de origen servil; ERSg 180, C(aius) Iul[i]u[s] Co[---], sin datar. En la provincia de Palencia todos los testimonios proceden de civitas de Palantia (Palencia): IRPPa 31, Iuli(a) Scauri fil(ia) y su hija Iulia Marcella, s. II d.C.; IRPPa 32, C(aius) Iulius C(aii) f(ilius) Quir(ina tribus) P[a]ternus, s. II d.C., de manera que siendo la condición jurídica de Palantia de municipio flavio, Paternus debió alcanzar los derechos de ciudadanía romana a través del ejercicio de las magistraturas, de hecho su madre Ata, dedicante de su epitafio, no lleva nomen y sí un idiónimo indígena (AlBerTos 1966, 41); IRPPa 62, Iulia Chrysis, s. II d.C., quizá una liberta, por su cognomen griego (SoLIN 1982, 1142, 1144); IRPPa 67, Licinia Iulia, sin datar. 
to de municipios flavios, ${ }^{15} \mathrm{y}$ en las que algunos Iulii manifiestan una preeminencia socioeconómica participando en las redes de dependencia personal y en las élites de dirección administrativa de la ciudad, como en Palantia. Un comportamiento singular al respecto presenta, sin embargo, el conjunto epigráfico de la provincia de Valladolid, en el que la presencia de Iulii está en la línea de la constatada en Palencia y Segovia en cuanto al número de casos, pero tratándose, el vallisoletano, de un corpus epigráfico infinitamente más reducido esta presencia cuantitativa le convierte aquí en el nomen más repetido. ${ }^{16}$ Hemos de concluir, por tanto, que en las fuentes epigráficas del área central de la Meseta norte el gentilicio presenta un mayor impacto en la provincia de Valladolid, si bien no se vincula claramente a determinadas civitates, como ocurre en las provincias de Segovia y Palencia.

Los conjuntos epigráficos de las provincias de Burgos y Soria constituyen el sector oriental de la Meseta norte. En ellos el nomen Iulius, como en los de Segovia y Palencia, está de entre los gentilicios más repetidos en la onomástica personal, pero sin resultar ser el protagonista. En Burgos los Iulii se ubican en Clunia, Segisamo (Sasamón) y Belorado, no mostrando signos de una especial preeminencia socioeconómica, excepto en Segisamo, donde aparecen implicados en redes de dependencia personal. ${ }^{17}$ En la provincia de Soria los Iulii se localizan en Alcubilla de Avellaneda, localidad muy próxima a Clunia y seguramente en su territorio, ${ }^{18}$ donde ya hemos visto que también se constata el gentilicio, así como en Termes, en el entorno de Uxama, y en el área de carácter rural deYanguas. ${ }^{19}$ Sin duda destaca uno de los testimonios de Termes, ya que se trata de un ecuestre, con un cursus honorum militar. De

15 Martino 2004, 308-309, y 346-347.

16 IRPVa 4, C(aius) Iul(ius) Aemiliu(s) m(iles) leg(ionis) VII [G(eminae?)], en Piña de Esgueva, primer tercio del s. III d.C.; IRPVa 7, Iulius, en Becilla de Valderabuey, ss. II-III, a quien dedicaría su mujer Eutichya (Solin 1982, 1230), nótese también el antropónimo griego, aunque nada más podemos afirmar dado que el epígrafe se encuentra desaparecido; IRPVa 19, [Am]ma Iu [lia], en San Martín de Valvení, sin datar; IRPVa 26, Iulius Proculus, en Montealegre, 134 d.C., en un ciudadano de Amallobriga (¿Tiedra?, civitas de status jurídico desconocido, MARTINo 2004, 204-206). Exceptuando este último, los restantes testimonios proceden de villae y enclaves rurales.

17 En Clunia tenemos CIRPBu 93, Iulia, que ofrece un voto a los Dii, ss. I-II, y CIRPBu 94, Iull[ius?], en el santuario priápico de la Cueva de San Román, s. I d.C. En Belorado, donde hubo un nucleo de población de status desconocido (Martino 2004, 130-131, 341), CIRPBu 31, Iulia Viganica Lasc[i]vif., s. II d.C., una indígena romanizada a juzgar por su cognomen indígena (AlBerTos 1966, 249); y en Segisamo, probable municipio flavio (MarTino 2004, 338) CIRPBu 570, Iul(ius) Morinus y Iul(ius) Eufemus (cognomen griego, Solin 1982, 711), artesanos y seguramente libertos privados en una excepcional tabula de patronato gremial, fechada en el 239 d.C., y CIRPBu 571, C(aius) Iu[lius...], ss. II-III d.C.

18 Vid. sobre ello GIMENO - RAMÍREz 2002, 273-274.

19 HEp 11, 480, G(aius) Iulius [---], vetera[nus leg(ionis)] y Iulius F(---) (dedicante, un liberto?), en Alcubilla de Avellaneda, 70-75 d.C.; ERPSo 127, G(aius) Iulius [--- ]Pomp[eianus], praef(ectus) coho(rtis), trib(unus) mil(itum) l(egionis), un ecuestre, en Montejo de Tiermes (Termes), primera mitad del s. II d.C.; PÉrez GonzÁlez ET ALII 2014, 132, n45, L(ucius) Iuli[---], en una tabula de bronce, sin duda un documento excepcional pero con graves deterioros, también en Termes, de época altoimperial; ERPSo 124, Iulius Gemelus, en Yanguas, s. I d.C.; también en la zona de Yanguas, HEp 11, 514, Marcus Iulius Balani f(ilius), en S. Pedro Manrique, s. I d.C.; ERPSo 47, C(aius) Iulius Barbarus Medutticorum C(aii) f(ilius) y su padre C(aius) Iulius Labeo Crastunonis f(ilius) Medutticum, en Barcebalejo, entorno de Uxama Argaela, s. I d.C. Éstos últimos casos de Yanguas y Barcebalejo corresponden a ciudadanos (romanos o latinos) indígenas romanizados, como evidencia el uso de antropónimos de origen prerromano, Balanus (PAlomar 1957, 47), Crastuno (AlBerTos 1966, 98), y el nombre de familia Medutticum (AlberTos 1966, 153-154). 
confirmarse su origen termestino, lo que dificulta el deterioro del documento, sería el miembro de la gens Iulia de más alto rango social de los ubicados en la Meseta norte. ${ }^{20}$ También resulta interesante el testimonio de Alcubilla de Avellaneda, que habría que ligar a Clunia, un veterano legionario, G(aius) Iulius [---], quizá patrono de Iulius F(---), dedicante de su epitafio, quien no porta praenomen.

Resulta, por tanto, que en la mitad oriental de la Meseta norte el nomen Iulius se localiza en las tres civitates de promoción más temprana de nuestro territorio, Clunia, Termes y Uxama, contando las tres con testimonios ya en el s. I d.C. ${ }^{21}$ Entre los testimonios de Iulii situados en ellas destaca el del veterano legionario G(aius) Iulius [---], en el entorno de Clunia, ya que es el único en el que el gentilicio Iulius pudiera vincularse con cierta seguridad a una promoción augustea. Habiéndose datado el epígrafe entre el 70-75 d.C., y de ser el veterano oriundo de la zona, de lo que no es posible tener seguridad, habría que pensar que éste pudo promocionarse a la ciudadanía romana a finales del gobierno de Augusto o en la etapa de Tiberio, período que nos lleva al momento de acceso de Clunia al estatus municipal, si bien tampoco podemos descartar que fuera beneficiario de una donación de ciudadanía a título individual. También en el s. I d.C. el gentilicio cuenta con testimonios en la zona rural soriana de Yanguas. ${ }^{22}$ En definitiva, el nomen Iulius manifiesta una sólida

20 Martino 2004, 183-184. El gentilicio Iulius arraigó en Termes, y de hecho conocemos un tercer caso, en un epígrafe hallado en Santa Eulalia de Almonaster, en un antiguo distrito minero de la provincia de Huelva, fechado a finales del s. I d.C., que recoge a L(ucius) Iuliu[s] L(uci) f(ilius) Campanus Tarmestinus.

21 Como en el caso de los emigrantes termestinos, vid. nota anterior, también emigrantes clunienses y uxamenses ofrecen algunos individuos portadores del nomen Iulius. Así I(u)l(i)u(s) Lucceiianus uxsa(mensis), en Pax Iulia (Beja), en un epitafio como mínimo ya del s. II d.C. (Gómez PAntoja 1998, 193 nº7). También ERPSo 153, epitafio de Licinius Iulianus uxamensis, puesto por madre Iulia, en Complutum (Alcalá de Henares, Madrid), finales del s. I o comienzos s. II d.C. (Gómez PAntoja 1998, 189 n²9). Y en Dacia conocemos CIL III, 1158, una dedicación votiva a la Victoria Augusta consagrada por L(ucius) Iul(ius) T(itii) [f(ilius)] Galer(ia tribus) Leuganus, natural de Clunia, veterano de la legio XIV Gemina, puesta también en nombre de su hijo C. Iulius Paternus, que seguramente servía en la misma legión, en Apulum-Alba Iulia, de finales del s. I o principios del s. II d.C.; se ha sugerido que Leuganus fuera reclutado en época de Nerón (HERNÁNDEZ GUERRA 2003, 238), lo que indica una promoción jurídica de él mismo, o de sus ascendentes (padre o abuelo), vinculada a la gens Iulia imperial, de época de Augusto o Tiberio. Ahora bien, hay que hacer notar que es escaso el impacto del nomen Iulius en la nómina de emigrantes clunienses y uxamenses que conocemos, ya que se reduce a tres casos en varias decenas de epígrafes (Gómez PANTOJA 2007, 347 nota 24 se refiere a sesenta y cinco casos en total más nueve dudosos).

22 EsPINOSA 1992, 903-908 señala la singularidad del conjunto epigráfico de la tierra de Yanguas, así como su datación temprana, su onomástica latinizada, aunque con pervivencias de antropónimos indígenas, así como la influencia en el terreno de sus denominaciones personales de la vecina Calagurris Iulia, municipio de derecho romano desde época augustea. GómEz PANTOJA - Alfaro 2001, 172-173, valoran la salubridad de las aguas de la zona de Yanguas como factor de atracción de foráneos de las ciudades próximas del alto valle del Ebro. Sin embargo, hay que hacer notar que no se ha constatado el nomen Iulius en la onomástica personal de Calagurris Iulia, ni en la epigrafía ni en las emisiones monetales, a pasar de la relación del municipio con la gens Iulia imperial (AMElA 2012, 133). GARRIDO - CASTILlo 1999, 233 dan a conocer a un M(anius) I(ulius?, -unius?) (segunda mitad s. I - inicio s. II d.C.), pero el deterioro del epígrafe hace imposible asegurar la lectura. Es cierto, como GARRIDO - CASTILlo 1999, 233 señalan, que el hecho de que los calagurritanus honraran como patrono en época de Domiciano a Titus Iulius Maximus Manlianus (CIL V, 6987; CIL XII, 3167), que fue legatus iuridicus en la Citerior, pudo dar lugar a la instauración real de la gens Iulia en el tejido socio-político de Calagurris a partir de la influencia de este personaje de prestigio; pero, en todo caso, la influencia del mismo, de haberse producido, lo que epigráficamente no puede ser corroborado, sería ya en época flavia, y, desde luego, ajena a la gens Iulia imperial. También en Calagurris conocemos el epitafio 
presencia onomástica en la mitad oriental de la Meseta en el s. I d.C., cuya explicación más factible pensamos que debe relacionarse con la influencia romanizadora y urbanizadora de la gens Iulia imperial en la zona. Más tardíamente, ya en la primera mitad del s. II d.C. situamos al ecuestre G(aius) Iulius [---]Pomp[eianus] en Termes, y a lo largo de esta centuria y en la siguiente, s. III d.C., la presencia del nomen Iulius se amplia también a otros puntos de la provincia burgalesa, como Belorado, núcleo indígena romanizado del que no conocemos promoción jurídica, Bergidum Flavium y Segisamo, ambos probables municipios flavios, en el último de los cuales los Iulii ejercen como patronos de libertos.

Por el contrario, en los sectores central y occidental de la Meseta, el único área en el que contamos con testimonios del nomen Iulius datados con seguridad en el s. I d.C. es en el territorio meseteño leonés. Dos de ellos se han datado hacia finales de la centuria, uno en Asturica Augusta, núcleo de origen augusteo, donde Iul(ius) Si(lo?)y Iul(ius) Flo(rus?) podrían ser dos libertos privados, lo que relacionaría de nuevo a los Iulii con redes de dependencia personal, y el otro en la localidad de Luyego, en el área de influencia de Asturica, que nos da a conocer a Iul(ius) Capito, mil(es) coh(ortis) I C[eltiberorum?], si bien en éste último caso no podemos descartar que el militar procediera de fuera del área leonesa de la Meseta. El tercer testimonio se sitúa en el ámbito de la civitas Vadiniensis, en Crémenes, el del veterano legionario M(arcus) Iulius Cr(escens), un epígrafe desaparecido datado en el s. I d.C. cuya interpretación es problemática. Podría pensarse en una promoción jurídica de Crescens en época de Augusto o Tiberio, como el veterano asentado en el área de Clunia mencionado supra, y si bien no hay constancia de que Crescens fuera oriundo de la Meseta norte pero tampoco puede descartarse. ${ }^{23}$ Ahora bien, dejando a un lado estos tres testimonios del s. I d.C., en el área central y occidental de la Meseta norte los testimonios de Iulii son habitualmente más tardíos, fechándose en su mayoría en los ss. II y III d.C., y comparativamente resulta un conjunto de datación más tardía que el reunido en el sector oriental de la Meseta norte. Se localizan sobre todo en civitates de promoción flavia segura o probable, así Segovia, Cauca, Palantia, Asturica Augusta, Bergidum Flavium, Salmantica. Llama la atención en este grupo la ausencia de Iuliobriga, civitas que, a pesar de su origen augusteo, luego municipio flavio, no contiene ningún Iulii en su corpus epigráfico. ${ }^{24}$ También les encontramos en algún núcleo de estatus no conocido, como Amallobriga (¿Tiedra?, Valladolid) y Petavonium (Rosinos de

de Iulius Longinus Doles Bessus (s. I d.C.), pero se trata de un militar auxiliar de origen extra-provincial. No parece pues que los Iulii de la zona de Yanguas estén relacionados con la onomástica calagurritana, ni por extensión con el valle del Ebro, en el que por lo demás la presencia de la gens es escasa, vid. UTRILLA Miranda 1979, 108; ABASCAL 1994, 151-163.

23 Palao 2009-2010, 91 nota 28 señala la dificultad de interpretación de la presencia de este veterano de la legio $X X$ en Crémenes, que se relaciona con la discusión sobre la participación de esta legión en las guerras cántabras. Para MARTINo 2012, 311 nota 35 es un individuo de origen foráneo, ajeno a los usos de la epigrafía vadiniense; pero ello no implica que no pudiera ser oriuendo de algún punto del territorio meseteño leonés o de otro lugar de la Meseta norte.

24 Aunque las fuentes epigráficas procedentes de Iuliobriga no son muy abudantes, no se halla en ellas el nomen Iulius, ni en los epígrafes del área ni en los de ciudadanos de la civitas recogidos en documentos fuera de su territorio, vid. MARTINo 2004, 283-286. Pero el hecho no es exclusivo, ya nos hemos referido en la nota 22 a que en Calagurris Iulia (Calahorra), ciudad promocionada a municipio romano por Augusto y 
Vidriales, Zamora), y en enclaves indígenas romanizados sin promoción jurídica, como la civitas Vadiniensis, Hinojosa de Duero y Saldeana (ambos en Salamanca), Moral de Sayago (Zamora). Igualmente se registran algunos testimonios en villae y enclaves de tipo rural, como Cimanes de la Vega, Villaquejida, Luyego de Somoza y Villalís, todos ellos en el territorio meseteño leonés, en Piña de Esgueva, Becilla de Valderabuey y S. Martín de Valvení en el territorio de Valladolid, en Montejo de la Vega en Segovia, en Narros del Puerto en Ávila, y en Boadilla y Cepeda en Salamanca.

Queda claro, por tanto, que el nomen Iulius aparece asentado en la onomástica personal de la Meseta norte como fecha más temprana en el s. I d.C., en las civitates promocionadas en la primera etapa del Principado, como son Termes, Uxama y Clunia en la mitad oriental, y en Asturica Augusta, ciudad de origen augusteo, en la mitad occidental, aunque también en esta primera centuria hallamos Iulii en áreas rurales, como la zona de Yanguas (Soria), o la zona vadiniense (León), en este caso un veterano legionario. A pesar de la datación genérica de la mayor parte de estos epígrafes en el s. I d.C., sin duda juntos constituyen una huella de la influencia onomástica de la gens Iulia imperial en este territorio, aunque resulte difícil vincular de forma inequívoca a estos individuos o sus ascendentes con una promoción jurídica en época augustea, con la posible excepción, como ya hemos señalado, de los veteranos legionarios, uno del área de Clunia (documento de Alcubilla de Avellaneda, Soria), otro en el área vadiniense (documento de Crémenes, León), y otro veterano cluniense en un epígrafe hallado en Dacia.

Desde el punto de vista social, el individuo con una promoción personal más alta en los Iulii de la Meseta norte es el ecuestre ya mencionado en Termes, en la primera mitad del s. II d.C. En la misma centuria otros dos miembros del grupo aparecen integrados en las élites de gobierno municipal, en las civitates de Asturica Augusta y Palantia, ambas promocionadas a municipios latinos en época flavia. Se trata de C. Iulius C. f. Quir(ina tribus) Fidus asturicensis, sacerdos Romae et Augusti, flamen designatus provinciae Hispaniae Citerioris, y de C. Iulius C.f. Quir(ina tribus) Paternus. Este último no menciona en su monumento el desempeño de magistraturas o cargos públicos, pero debió de alcanzar los derechos de ciudadanía romana a través del ejercicio de la magistratura municipal en el municipio flavio de Palantia. De hecho su madre Ata, dedicante de su epitafio, no lleva nomen y sí un idiónimo indígena, por lo que ella no es ciudadana romana, mientras que su hijo claramente sí lo es, como indica su tribu. En todo caso, ambos individuos constituyen un ejemplo elocuente de que la presencia del nomen Iulius en el esquema onomástico de un individuo no necesariamente tiene que ir ligado a una promoción jurídica relacionada con la gens Iulia imperial por parte de su portador. Tanto Fidus en Asturica, como Paternus en Palantia, son ciudadanos romanos promocionados jurídicamente gracias a la aplicación del ius Latii donado por el emperador Vespasiano a Hispania, y que convirtió a sus respectivas civitates en municipios latinos flavios, como indica su adscripción a la tribus Quirina. Sin embargo, eligen Iulius como nomen de su nuevo

muy vinculada a la gens imperial Iulia (recuérdese la guardia calagurritana del emperador), no se registra igualmente el nomen Iulius en su onomástica personal. 
esquema de tria nomina romano. Sin duda Iulius era por entonces un referente de romanidad prestigiosa. En el caso de Fidus, o de sus ascendentes (puede que él no fuera un ciudadano romano de primera generación), pudo pesar además en su elección la estrecha vinculación entre Augusto y el origen de su civitas de origen, Asturica. Cabe también la posibilidad de que en ambas familias, la de Fidus en Asturica y Paternus en Palantia, se utilizara y transmitiera el nomen Iulius ya con anterioridad a la promoción efectiva de alguno de sus miembros a la ciudadanía romana, dada la flexibilidad de los esquemas onomásticos de los latinos provinciales, que a menudo incorporaban a su onomástica el uso de un nomen romano, sobre todo en esquemas de duo nomina seguidos de patronímico, aunque no hubieran alcanzado todavía la promoción a la ciudadanía romana. ${ }^{25}$

Pero además de en Asturica y en Palantia, es posible que los Iulii alcanzaran las magistraturas municipales también en Salmantica, igualmente municipio flavio, donde ya hemos indicado que constituyen una de las familias de notables de la civitas, dada la calidad sobresaliente de alguno de sus monumentos epigráficos y su carácter de patronos de libertos. El patronazgo de libertos es signo sin duda de una situación económica privilegiada, y además de en Salmantica, miembros de los Iulii lo ejercen en Asturica, Segovia, Palantia y Segisamo. El elenco de la élite social de los Iulii de la Meseta norte se completa con la existencia de dos veteranos legionarios, en Clunia y Crémenes (León), y un legionario en Piña de Esgueva (Valladolid). Desde el punto de vista onomástico hemos podido comprobar que los Iulii de la Meseta norte forman un grupo altamente romanizado, en el que abundan los esquemas de tria nomina (en dos casos con mención de la tribus) y duo nomina, las filiaciones de estilo romano más que los patronímicos de tradición indígena, y los cognomina latinos y griegos sobre los de origen indígena prerromano. ${ }^{26}$

25 Alföldy 1966, 47-55; Mangas 1996, 237; DARDAine 1999, 213-228; GARCía FernándeZ 2001, 140-145; GARCía Fernández 2007, 234 y 236. La discusión historiográfica en torno al asunto del esquema onomástico de los ciudadanos latinos está bien sintetizada en CIPRÉs 2006, 112-113. La misma CIPRÉS 2006, 119 se inclina por atribuir la estructura de nomen+cognomen+patronímico, muy habitual en áreas en proceso de romanización, como es la Meseta norte, a ciudadanos romanos que omiten ya su praenomen (situación que se evidencia por evolución del esquema onomástico romano desde mediados del s. II d.C.) y adoptan una influencia autóctona en su filiación, o bien a individuos afectados por la concesión del ius Latii en sus comunidades. Rotunda y definitiva la aportación a esta discusión de GARCía Fernández 2010, 145-155, donde se insiste además en los efectos de la latinidad en el connubium, como posibilitadora de uniones mixtas entre ciudadanos romanos y latinos que se situarían bajo el ius civitatis del varón, ya expresado en GARCíA FERNÁNDEZ 2001, 146-150. Vid. también EsPINOSA EsPINOSA 2009, 237-247; GARCía FERNÁNDEZ 2011, 47-66 y GARCía FERNÁNDEZ 2012, 423-436.

26 Únicamente en dos casos el nomen Iulius aparece como nombre único, fuera de esquemas de tria nomina y duo nomina, ERAv 131, Iulius y CIRPBu 93, Iulia (vid. GALlego 2012, 131-149). Hemos visto los antropónimos indigenas que conservan Iulia Amma (ERPLe 177), Amma Iulia (IRPVa 19, parece un caso de inversión del nomen, fenómeno conocido en los esquemas onomásticos de los indígenas romanizados del valle del Duero, Gorrochategui ET ALII 2007, 296), Iulia Viganica (CIRPBu 31) y los patronímicos indígenas de C. Iulius Labeo Crastunonis f. (ERPSo 47) y Marcus Iulius Balanif. (HEp 11, 514, otro caso de inversión del nomen). C.Iulius Labeo Crastunonis $f$. y su hijo C. Iulius Barbarus portan además un nombre de familia prerromano, Medutticorum/Medutticum. Algunos de ellos portan también cognomina latinos populares entre los indígenas romanizados, como Flavus (ERSg 84), Paternus (ERPLe 14; IRPPa 32), Vegetus (ERPLe 184; FE 327), Capito (ERPLe 181, 238), Oculatius (ERPLe 185). Sobre el carácter de decknamen de estos cognomina vid. Navarro Caballero 1998, 186 nota 53 (para Flavus); Abascal 1984, 219 ss, Navarro 
En cuanto a la epigrafía votiva relacionada con Iulii en la Meseta norte, ésta se vincula especialmente con enclaves rurales, a menudo bien situados respecto a la red viaria, como la doble dedicación a Hercules de Montejo de la Vega de la Serrezuela en Segovia, o las dos aras consagradas a Iuppiter Optimus Maximus en Salamanca, una en Boadilla y otra en Cepeda, que constituyen, como ya hemos señalado, dos de los documentos más romanizados dentro de la religiosidad de la provincia de Salamanca constatada a través de la epigrafía; o las dos aras del santuario de Narros del Puerto (Ávila), una consagrada a Deus Iuppiter y otra a los Lares Viales, dándose la circunstancia de que en el mismo lugar se constata también el culto a la divinidad vetona Ilurbeda, relacionada igualmente con el territorio salmantino, en el que el gentilicio Iulius resulta ser el más repetido, como ya hemos visto. La actividad votiva de los Iulii en la Meseta norte se completa con una dedicación a la divinidad indígena Cossue en Bergidum Flavium, y un voto a los Dii, pro fortuna, en Clunia. En definitiva, un panorama de aculturación religiosa propio de indígenas romanizados. ${ }^{27}$

En base al análisis de las fuentes epigráficas podemos concluir, por tanto, que el nomen Iulius aparece en la Meseta norte vinculado sin duda a la influencia de la gens Iulia imperial, ya que los documentos epigráficos más tempranos del gentilicio apuntan a ello, en especial los relacionados con veteranos legionarios, así como la propia presencia del nomen en los municipios preflavios de Clunia, Termes y Uxama, y en la civitas de Asturica Augusta, de fundación augustea. En el patrón de dispersión territorial del nomen en la Meseta norte contamos también con ausencias notables, como en la civitas de Iuliobriga, aunque esta situación no resulta absolutamente novedosa, y en este sentido nos hemos referido a la ausencia del nomen Iulius en la onomástica personal de la epigrafía de Calagurris Iulia y del valle del Ebro. Ahora bien, el atractivo del nomen como referente de romanidad prestigiosa se manifiesta en el hecho de que éste sea adoptado por algunos nuevos ciudadanos, tanto romanos como latinos, promocionados jurídicamente en el marco de la conversión de sus civitates en municipios latinos flavios, con seguridad en Palantia, Asturica y Salmantica. Probablemente esta circunstancia se produjo en alguno más, dado el protagonismo de los municipios flavios en el patrón de distribución del gentilicio Iulius en la Meseta norte, y el hecho conocido de que es la etapa de municipalización flavia la responsable, en sustancia, de la promoción jurídica de la mayoría de las civitates de la Meseta norte que alcanzaron el estatus municipal. Fruto de ese prestigio del nomen Iulius, que por otro lado probablemente ganara peso ya a partir de finales del s. I d.C., a

\footnotetext{
CABallero 1998, 186 nota 53 y Esteban 2000, 252 (para Paternus); Ramírez SÁDABa 2001, 232, y Ramírez SÁdaba 2009, 221 (para Vegetus); Navarro Caballero 1998, 181-182 notas 34 y 38 y 186 nota 53 (para Capito); Solin - Salomies 1988, 130 y Pérez Rojas 1993, 237 nota 180 (para Oculatius, Oculatianus).

27 Palao 2007, 259-260; Hernando Sobrino 2005a, 153-164, que relaciona a Ilurbeda con los pasos montañosos y la ganadería trashumante; OLIVARES PEDREÑo 2007, 149-150, 154 en cambio vincula a Ilurbeda con los movimientos migratorios ligados a las explotaciones mineras, e igualmente a Cossue, que pone en relación con el Cosus galaico. Vid. también Perea Yébenes 1998, 167-180 y Marco Simón 2002, 17-19 sobre las dedicaciones a Diis y fórmulas similares. Carácter excepcional tienen las dedicaciones votivas de Iulius Silvanius Melanio, procurator Augustorum, en Asturica, consagradas a la Tríada Capitolina (ERPLe 41), a Serapis e Isis (ERPLe 60) y a la Bona Fortuna y Nemesis (ERPLe 61), ya que se trata de un personaje de origen foráneo, no natural de la Meseta norte, cuya sensibilidad religiosa no puede ser, por tanto, representativa de la de los Iulii autóctonos de la Meseta norte, y, de hecho, difiere mucho de la mostrada por éstos.
} 
medida que iba resultando cada vez más remota en nuestro territorio la memoria de los viejos referentes onomásticos republicanos ${ }^{28}$ se produce también la presencia del mismo en la onomástica personal de inscripciones romanas encontradas en áreas rurales y núcleos indígenas romanizados sin promoción jurídica.

\section{BiBLIOGRAFÍA}

Abascal Palazón, J. M.

(1984): "Los cognomina de parentesco en la Península Ibérica. A propósito del influjo romanizador en la onomástica", Lucentum 3, 219-259.

(1994): Los nombres personales en las inscripciones latinas de Hispania, Murcia.

Albertos Firmat, $M^{\mathrm{a}}$ L.

(1964): "Nuevos antropónimos hispánicos", Emerita 32, 209-252.

(1966): La onomástica personal primitiva de la Hispania Tarraconense y Bética, Salamanca.

AlföLdy, G. (1966): "Notes sur la relation entre le droit de cité et la nomenclature dans 1'Empire romain", Latomus 25/1, 37-57.

Alonso Ávila, A. - Crespo Ortiz de ZÁrate, S.

(1999): Corpus de inscripciones romanas de la provincia de Salamanca (CIRPSa), Valladolid.

(2000): Corpus de inscripciones romanas de la provincia de Zamora (CIRPZa), Valladolid.

Amela Valverde, L. (2012): "Las dos primeras emisiones latinas de la ciudad de Calagurris", Kalakorikos 17, 127-146.

Cepeda Ocampo, J. J. - Iglesias Gil, J. M. - Ruiz Gutiérrez, A. (2009): “El foro romano de Iuliobriga (Cantabria). Nuevas investigaciones arqueológicas”, AEspA 82, 97-114.

CIPRÉs, P. (2006): "La onomástica de las inscripciones romanas del País Vasco. Estructura del nombre personal y estatuto jurídico", Veleia 23, 85-128.

Crespo Ortiz de Zárate, S. - Alonso Ávila, A.

(2000): Corpus de inscripciones romanas de la provincia de Burgos (CIRPBu), Valladolid. (2000): Auctarium a los corpora de epigrafía romana del territorio de Castilla y León. Novedades y revisiones (AuCERCyL), Valladolid.

DARDAINE, S. (1999) : “Les affranchis des cités dans les provinces de l'Occident romain: statut, onomastique et nomenclature", [en] J. González Fernández (ed.), Ciudades privilegiadas en el Occidente romano, Sevilla, 213-228.

EsPinosa EspinosA, D. (2009): "El ius Latii y la integración jurídica de Occidente. Latinización vs. romanización”, ETF, Serie II, $H^{a}$ Antigua 22, 237-247.

EsPINOSA, U. (1992): "Los castros soriano-riojanos del Sistema Ibérico: nuevas perspectivas", [en] $2^{\circ}$ Symposium de Arqueología Soriana (Soria, 1988), Soria, 901-913.

\footnotetext{
28 Es conocida desde hace tiempo la popularidad en la nomástica personal de Hispania recogida en las fuentes epigráficas, también en su mitad norte, de los nomina portados por los generales y gobernadores romanos republicanos, responsables de la conquista y pacificación de la Península Ibérica, vid. por ejemplo GORROCHATEGUI ET ALII 2007, 308-310.
} 
Esteban Ortega, J. (2000): "El proceso de romanización en Lusitania a través de la epigrafía", [en] J. G. Gorges - T. Nogales Basarrate (coords.), Sociedad y cultura en Lusitania romana, Badajoz, 249-268.

Gallego Franco, H.

(2001): Nomina Imperatoria: Onomástica Imperial en la Sociedad de las Provincias Romanas del Alto y Medio Danubio, Valladolid.

(2012): “Onomástica y estatuto jurídico individual. Las denominaciones personales de nomen único en la epigrafía romana de Castilla y León”, Hispania Antiqua 36, 131-149.

GARCía FERnÁndez, E.

(2001): El municipio latino. Origen y desarrollo constitucional, (=Anejos de Gerión 5), Madrid.

(2007): "Ni ciudadanos ni extranjeros: la condición jurídica de la población provincial", [en] J. Mangas - S. Montero Herrero (coords.), Ciudadanos y extranjeros en el mundo antiguo: segregación e integración, Madrid, 227-240.

(2010): "Latinidad y onomástica en el Noroeste peninsular", [en] I. Sastre - A. Beltrán (eds.), El bronce de El Picón (Pino del Oro). Procesos de cambio en el Occidente de Hispania, Zamora, 145-155.

(2011): "Movilidad onomástica e integración en Hispania en época republicana: algunas observaciones metodológicas", [en] J. M. Iglesias - A. Ruiz (eds.), Viajes y cambios de residencia en el mundo romano, Santander, 47-66.

(2012): "Sobre la condición latina y su onomástica: los ediles de Andelo", ETF, Serie II $H^{a}$ Antigua 25, 423-436.

GARCÍA Martínez, R. (2000): Germania romana. Las estructuras sociales, Valladolid.

Garrido Moreno, J. - Castillo Pascual, P. (1999): Nuevos testimonios epigráficos en Calahorra", Kalakorikos 4, 231-235.

Gimeno Pascual, H. - Ramírez Sánchez, M. (2002): “Dos inscripciones inéditas de la provincia de Soria (España)", ZPE 139, 273-278.

Gómez Pantoja, J. - Alfaro PeÑa, E. (2001): "Indigenismo y romanización en las tierras altas de Soria", [en] F. Villar - M ${ }^{\mathrm{a}}$ P. Fernández (coords.), Religión, lengua y culturas prerromanas de Hispania, Salamanca.

Gómez Pantoja, J.

(1998), “Celtíberos por el mundo”, [en] J. Alvar (ed.), Homenaje a José Má Blázquez, vol. $V$, Hispania Romana II, Madrid, 183-201.

(2007): "Una tierra de emigrantes", [en] M. Navarro - J. J. Palao (eds.), Villes et territoires Dans le bassin du Douro à l'époque romaine, (=Études 17), Bordeaux, 341-353.

GonzÁlez Fernández, Ma L. (2012): “Origen militar y desarrollo urbano de Asturica Augusta”, [en] J. Beltrán Fortes - O. Rodríguez Gutiérrez (coords.), Hispaniae urbes. Investigaciones arqueológicas en ciudades históricas, Sevilla, 257-294.

Gorrochategui Churruca, J. - Navarro Caballero, M. - Vallejo Ruiz, M. (2007): "Reflexiones sobre la historia social del valle del Duero: las denominaciones personales", [en] M. Navarro Caballero - J. J. Palao Vicente (eds.), Villes et territoires dans le bassin du Douro á l'èpoque romaine. Actes de la table-ronde internationale (Bordeaux, septiembre 2004), Bordeaux, 287-339.

Hernando Sobrino, $\mathrm{M}^{\mathrm{a}} \mathrm{R}$.

(2005): Epigrafía romana de Ávila (ERAv), Bordeaux-Madrid.

(2005a): “A propósito del teónimo Ilurbeda. Hipótesis de trabajo”, Veleia 22, 153-164. 
HERNÁNDEZ GUERRA, L.

(1994): Inscripciones romanas de la provincia de Palencia (IRPPa), Valladolid.

(2001): Epigrafía de época romana de la provincia de Salamanca, Valladolid.

(2003): "Los desplazamientos de clunienses en época romana. Población y onomástica", Sautuola 9, 229-251.

Jimeno, A. (1980): Epigrafía romana de la provincia de Soria (ERPSo), Soria.

López Ambite, F. (2002): "El castro de la Antipared (Montejo de la Vega de la Serrezuela, Segovia): en la frontera de la Celtiberia", BSAA 68, 77-104.

MANGas Manjarrés, J. (1996): “Derecho latino y municipalización en la Meseta superior”, [en] Teoría y práctica del ordenamiento municipal en Hispania, Revisiones de Historia Antigua, II, Vitoria, 223-238.

Mañanes PÉRez, T. - Solana SÁInz, J. Ma (1999): Inscripciones de época romana de la provincia de Valladolid (IRPVa), Valladolid.

Marco Simón, F. (2002): “Diis Deabusque. A indefinicâo primordial do divino”, [en] J. Car$\operatorname{dim}$ (coord.), Religiôes da Lusitania. Loquuntur saxa, Lisboa, 17-19.

MARTINO GARcía, D.

(2004): Las ciudades romanas de la Meseta norte de la Península Ibérica: identificación, estatus jurídico y oligarquías (ss. I-III d.C.), Madrid.

(2012): “Acerca de la cronología de la epigrafía Vadiniense. Revisión historiográfica y nuevas propuestas", ETF Serie II, Historia Antigua 25, 305-326.

Navarro Caballero, M. (1998): "Las estelas en brecha de Santo Adriâo: observaciones tipológico-cronológicas”, BSAA 64, 175-206.

NúÑEz Hernández, S. - CurChin, L. A. (2007): “Corpus de ciudades romanas en el Valle del Duero", [en] M. Navarro Caballero - J. J. Palao Vicente (eds.), Villes et territoires Dans le bassin du Douro à l'époque romaine, (=Études 17), Bordeaux, 432-612.

Olivares Pedreño, J. C. (2007): "Hipótesis sobre el culto al dios Cossue en el Bierzo (León): explotaciones mineras y migraciones”, Palaeohispanica 7, 143-160.

Palao Vicente, J. J.

(2007): "Epigrafía y sociedad en la provincia de Salamanca durante la época imperial", [en] M. Navarro Caballero - J. J. Palao Vicente (eds.), Villes et territoires Dans le bassin du Douro à l'époque romaine, (=Études 17), Bordeaux, 239-268.

(2009-2010): "El regreso de los veteranos legionarios hispanos a la Península Ibérica", HAnt 33-34, 85-110.

Palomar Lapesa, M. (1957): La onomástica personal primitiva de la antigua Lusitania, Salamanca.

Perea Yébenes, S. (1998): “Las fórmulas epigráficas deus, deaeve, si deus si dea y diis deabusque", Veleia 15, 167-180.

Pérez González, C. - Illarregui Gómez, E. - Arribas Lobo, P. (2014): “Tiermes 2013. Intervención arqueológica y parerga epigráfica”, Oppidum. Cuadernos de investigación 10, 107-146.

PÉREz RojAs, M. (1993): "Las inscripciones con escritura tartésica de la cueva de La Camareta y su contexto onomástico (Aportaciones sobre la "celtización" del mundo ibérico tartésico)", [en] La cueva de La Camareta, (=Antigüedad y Cristianismo 10), 139-266. 
Rabanal Alonso, M. A. - García Martínez, S. (2001): Epigrafía romana de la provincia de León: revisión y actualización (ERPLe), León.

RAmírez SÁDABA, J. L. (2001): “Onomástica indígena en la Beturia céltica”, [en] F. Villar - M $\mathrm{M}^{\mathrm{a}}$ P. Fernández Álvarez (eds.), Religión, lengua y cultura prerromanas de Hispania, Salamanca, 227-240.

Santos Yanguas, J. - Hoces de la Guardia Bermejo, A. L. - Del Hoyo Calleja, J. (2005): Epigrafia romana de Segovia y su provincia (ERSg), Segovia.

Solin, H. (1982): Die griechische Personennamen in Rom, Berlín / New York.

Solin, H. - SAlomies, O. (1988): Repertorium nominum gentilium et cognominum latinorum, Hildesheim-Zürich-New York.

Utrilla Miranda, P. (1979): “Gentes en el convento jurídico caesaraugustano según la epigrafía y la numismática”, Cuadernos de investigación: Geografía e Historia 5/2, 95-133. 